\title{
Decisions Based on Synthesis Documents Information of the ABC (Activity-Based Costing) Method
}

\author{
Gary Cokins \\ SAS Institute Inc., \\ Cary, North Carolina, USA \\ Tel: 248-642-1296Ｅ-mail: garycokins@sas.com \\ Sorinel Căpuşneanu (Corresponding author) \\ Faculty of Finance and Accounting, Artifex University \\ 47 Economu Cezarescu Street, Romania \\ Tel: +40-720-398-735Ｅ-mail: sorinelcapusneanu@gmail.com
}

\author{
Cristian-Marian Barbu \\ Faculty of Finance and Accounting, Artifex University \\ 47 Economu Cezarescu Street, Romania \\ Tel: +40-745-162-780 E-mail: barbu_cristianmarian@yahoo.com
}

Received: August 27, 2011 Accepted: September 09, $2011 \quad$ DOI: 10.5296/ijafr.v1i1.905

\begin{abstract}
This article presents the synthesis documents specific to the Activity-Based Costing (ABC) method, based on their definition, composition and typology. The article describes the defining elements of the synthesis documents in their capacity of instruments for measuring and monitoring the performance of an entity and the role of these instruments in the formation of a "general dashboard". The dashboard allows visualization of overall trends tracked by the entity and helps managers in making appropriate decisions. The article ends with the authors' conclusions about the benefits of these synthesis documents, specifically to the $\mathrm{ABC}$ method, in their use as the main source for correct management decisions.
\end{abstract}

Keywords: Activity-Based Costing, dashboard, balanced scorecard, benchmarking, synthesis documents, result account, analysis. 


\section{Introduction}

In a century of fast-circulating information and a changing business environment, we have to adapt ourselves to the informational needs in order to take decisions that may shape the short or long term fate of an entity. In order to adapt itself to the market requirements and to the competitive environment, an entity must have effective tools for data analysis. One of the main sources can be developed by the entity's Accounting Department, along with other specific tools of control and cost analysis. A fair and well-founded decision is the key to business success and a guarantee of an efficient performance management.

\subsection{Background of the Study}

In performing this article, we started from the existence and importance of the accounting synthesis documents of financial accounting in Romanian entities, according to the Accounting Law no. 82/1991, republished in 2008 and updated in 2010. According to this law, the composition of financial statements is presented as follows: "For nonprofit organizations, annual financial statements consist of the balance sheet exercise, accounting policies and explanatory notes" (Chapter IV, Art. 28, paragraph 6).

\subsection{Gap Identification}

According to the Accounting Law no. 82/1991, management accounting is required to apply to all businesses: "Public institutions, associations and other legal and non-profit organizations and individuals engaged in producing income are also required to organize and run their own accounting, financial accounting, respectively, and where appropriate, management accounting "(Chapter I, Art. 1 paragraph 2). In Romanian entities that apply management accounting and not only, there is another set of official accounting synthesis documents that highlight the internal financial situation, which is the main reason for writing this article and for the proposals of the layout, preparation and presentation of the main components.

\subsection{Purpose and Objectives of the Study}

The purpose of this article is to present a set of synthesis documents obtained on the basis of management accounting data in Romanian companies that apply the Activity-Based Costing (ABC) method. As the international literature has not yet reached a consensus on the use of documents considered as "synthesis," our objective consists in the elaboration a set of documents designed to help create an overall picture in terms of making valid and relevant decisions by managers. This article is intended for all managers and professionals interested in a set of standard synthesis documents of management accounting, similar to those in financial accounting, but focused on the specifics of the ABC method. Of course, we offer only a model to start with for gathering the necessary information for complex analysis from both the heads of departments and managers of various organizations.

\section{Research questions}

This article intends to explore our attempt to create, adapt and use the information concentrated in the accounting synthesis documents in management accounting. In this sense were measured the judgment of the managerial accounting professionals from Romania, and 
of the managers from various public and private companies. We tried to find answers to the following questions:

1. In order to draw up accounting synthesis documents, how will they take data from financial accounting management accounting, according to the specific method of $\mathrm{ABC}$ ?

2. Does the $A B C$ method provide sufficient information to achieve an effective cost control and analysis?

3. The information contained in the records is relevant for the management and for taking complex management decisions?

\section{Literature reviews}

Following research by many specialists in management accounting, we have identified four patterns of results accounts in the literature.

The first model type identified, the functional results account type, is the best known and generally accepted only in the countries of monism accounting practitioners. Being found in the financial accounting, the classification of expenditure is made in relation to the functions of an enterprise according to the way of structural organization and its management accounting. In reality, this model has more disadvantages than advantages. Due to territorial independence, wrong decisions may be taken that would eventually lead to lower overall level of enterprise profitability (Collis and Hussey, 2007).

The second model identified, the list results account type, is the most widely used in countries accounting practitioners of dualism as a more favorably seen form of communication of financial performances of an enterprise, regardless of the sector of activity. The advantage of this model is limited to the "added value" that is defined by reference to two key success factors, namely: the market and the customer. Judging by the accounts, the management accounting can be organized in two versions: either by integrated organization with the use of different analytical in the financial accounting or either by dissociated organization with the use of accounts (Ebbeken and al, 2000).

The third model, the partial results account type is characterized by the ability to easily determine specific indicators (break point, cover factor) being comfortable for the management when taking decisions, particularly in the short term. However, it requires a separation of variable and fixed costs in pursuing this type of results account (Feleagă and Malciu, 2002).

An interesting possibility for determining the analytical result can be seen in the case of Activity-Based Costing (ABC) method. The total amount of values activities allows providing of a list of ignored expenses, and still essential for managing an enterprise. In an allocation by functional service, which the enterprise knows but this does not allow identification of the real causes of the costs development, the ABC method (Activity-Based Costing) substitutes a new results account in which the expenditure lines are not by their nature, neither their costs of different functional services but the resources consumed per activities. Thus the fourth model of results account appears, namely the results account on 
activities that best matches the requirements of the $\mathrm{ABC}$ method, transversality and processes structured into activities.

\section{Methodology}

\subsection{Instrumentation}

Research designing is focused on addressing the theoretical implications arising from development issues described by the questions launched at baseline. For the relevance of the study, we used questionnaires and two main types of answers to the questions were taken into account. The first category consists of specialists in management accounting (management accountants) and managers of entities (heads of departments, heads of senior management).

\subsection{Sample and data analysis}

The design study sample was drawn from a total of 215 people, according to the categories listed above. After collecting the questionnaires and gathering the data, the situation is as follows:

\begin{tabular}{|l|c|c|c|}
\hline \multicolumn{1}{|c|}{ Category of respondents } & Pro & Against & Total \\
\hline 1. Specialists & $79,06 \%$ & $20,94 \%$ & $100 \%$ \\
\hline 2. Managers of entities & $75,34 \%$ & $24,66 \%$ & $100 \%$ \\
\hline
\end{tabular}

As it can be seen, 170 specialists (79.06\%) support the creation and use of synthetic accounting documents and the entities that support among managers has 162 people $(75.34 \%)$. Starting from this situation, our empirical study continued and the results obtained following the design and the presentation of accounts synthesis are described below.

\section{Synthesis documents of the ABC method. Definition, composition, analogy}

Synthesis documents specific of the ABC (Activity-Based Costing) method are a set of documents based on accounting data (information) collected, aggregated and summarized in relation with the issues pursued by the entity's managers. Investigations conducted and documented within companies in Romania revealed that the synthesis documents specific to the $\mathrm{ABC}$ method can be composed of: the profit and loss account of $\mathrm{ABC}$ method, $\mathrm{ABC}$ dashboard, balanced scorecard, benchmarking, cost-volume-profit analysis etc. Compared with the synthesis documents of financial accounting, consisting of balance sheet, profit and loss account and specific annexes which are intended for external users such as the government regulatory agencies/ministries, shareholders (investors), banks, other third parties etc., synthesis documents specific of the management accounting are destined only for internal users (top management, department managers). Regardless of the general pattern of synthesis documents for management accounting, it will always have a confidential nature, not intended for users outside the entity. The similarities between synthesis documents of financial accounting and managerial accounting are the following:

1. Information from management accounting and financial accounting should be verifiable, according to documents;

2. The information obtained should be sub-operational. 
The differences between the synthesis documents of financial accounting and managerial accounting ( $\mathrm{ABC}$ method) are identifying from four points of view:

1. In terms of reporting: in the financial accounting the information obtained relates to a financial year; in the managerial accounting the information obtained is reported at frequent intervals (quarterly, monthly).

2. In terms of purpose: the financial accounting provides information to management and external users; the managerial accounting provides information only to management and employees for internal analysis and decisions.

3. In terms of users: the financial accounting provides information that is intended for both external and internal users (physical and legal persons); the managerial accounting provides information only for internal users, top management, department managers, and employees.

4. In terms of external publication (disclosure): in the financial accounting the information is published; in the managerial accounting the information is not published.

5. In terms of decision purpose: in the financial accounting the information is used in decisions regarding both financial activities and operating activities of the economic unit; in the managerial accounting the information is used in analysis and decisions regarding strategic and operating activities of the economic unit.

The purpose of the synthesis documents of the $\mathrm{ABC}$ method is to provide an overview of the developments pursued by the management of an enterprise through objectives and making decisions relevant to proper management. The main source of the information required for defining the accounting synthesis documents for the $\mathrm{ABC}$ method is the profit and loss account statement of the ABC method (Figure 1).

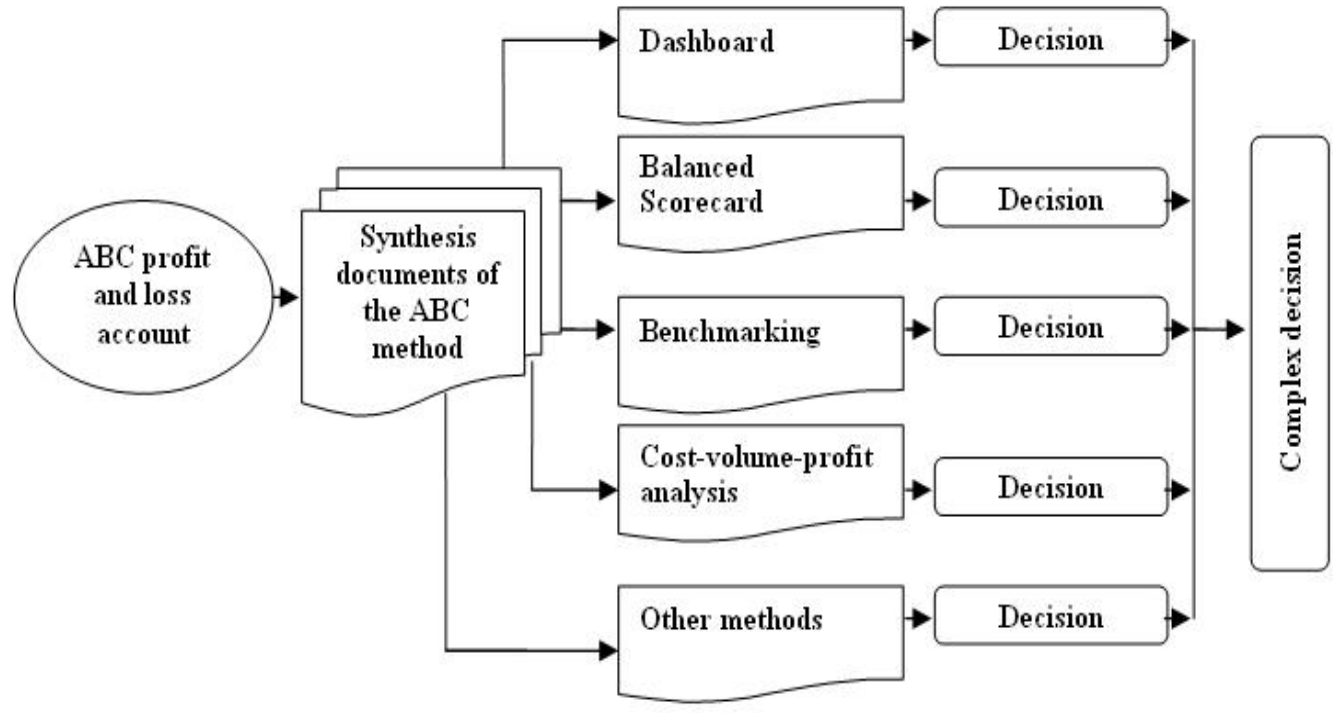

Figure 1. Formation and the ultimate goal of accounting synthesis documents 
6. Synthesis documents of the ABC method. Definition, composition, analogy

\subsection{The Profit and Loss Account}

The activity profit and loss account $(\mathrm{ABC})$ represents that synthesis document of management accounting. It allows viewing of earnings and/or losses that best fits the requirements of the $\mathrm{ABC}$ method, in terms of transversality and processes structuring per activities.

Architecture of the transversal organization describes the most important strategic actions to establish processes, activities and operations. Here are described the actions of an operational and detailed manner, while regrouping operations activities and processes as a logical outcome of the client. Transversal organization defines the quantitative employee's needs for each activity or operation. They also provide a situation in qualitative terms, through introducing the notion of competence (Ravignon et. all, 2003, p.302). Transversal organization highlights the company needed links to implement activities and related operations. They describe the relationship where responsibilities are exercised. The transversal organization of the enterprise defines through the concepts of frequency and capacity when actions become feasible. Ensure that the company is able to produce what has been determined on the strategic plan, taking into account available resources (employees, equipments, computer environments etc.). Source of data underlying the preparation of the profit and loss account statement of the ABC method (Figure 2) is: Journal Register, which in turn gathers data from the catalog of activities, list of costs drivers etc.

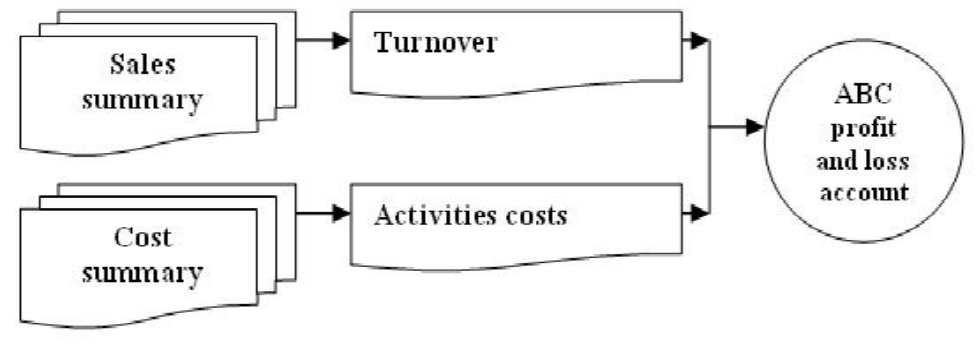

Figure 2. Training schedule and preparation of profit and loss account of the ABC method

After ABC profits and costs are calculated, heads of operational services are often surprised by the substantial change in product costs compared to their "beliefs" from the traditional externally reported cost information with its error-filled non-causally based calculations (although the errors sum to zero). Most resource-consuming activities cause losses or at least influence it. However, least-consuming activities that are essential for the client input value trigger reactions in order to increase the budget (Ravignon et. all, 2003, p. 260). The leaders of the functional services more easily understand these various reactions because the usefulness of the work displayed is easier to identify. This approach serves as a guide for action. In this respect, two profit and loss accounts may be established per activity: global (business) and per product. A more comprehensive picture is obtained when comparing the profit and loss account of many global products: 
Table 1. Example of profit and loss account at the enterprise level

\begin{tabular}{|l|l|}
\hline Explanations & Method of calculation \\
\hline 1. Turnover & $\ldots$ \\
\hline 2. Direct costs & $2.1 .+2.2$. \\
\hline 2.1. Consumption of raw materials & $\ldots$ \\
\hline 2.2. Direct salary cost + accessories of direct wages & $\ldots$ \\
\hline 3. Activities costs & $\sum 3.1 .+3.2+\ldots 3 . n$ \\
\hline .. & \\
\hline 4. Total costs & $2+3$ \\
\hline 5. Result (profit or loss) & $1-4$ \\
\hline
\end{tabular}

Table 2. Example of result account broken down by activity for "N" products

\begin{tabular}{|c|c|c|c|c|}
\hline Explanations & $\begin{array}{l}\text { Method of } \\
\text { calculation }\end{array}$ & $\begin{array}{c}\text { Product } \\
1\end{array}$ & $\begin{array}{c}\text { Product } \\
\ldots\end{array}$ & $\begin{array}{c}\text { Product } \\
\mathrm{N}\end{array}$ \\
\hline 1. Turnover & $\ldots$ & $\ldots$ & $\ldots$ & $\ldots$ \\
\hline 2. Direct costs & $2.1 .+2.2$ & $\ldots$ & $\ldots$ & $\ldots$ \\
\hline 2.1. Consumption of raw materials & $\ldots$ & $\ldots$ & $\ldots$ & $\ldots$ \\
\hline $\begin{array}{l}\text { 2.2. Direct salary costs }+ \\
\text { accessories of direct wages }\end{array}$ & $\ldots$ & $\ldots$ & $\ldots$ & $\ldots$ \\
\hline 3. Margin on direct costs & $1-2$ & $\ldots$ & $\ldots$ & $\ldots$ \\
\hline 4. Activities costs & $\sum 4.1 .+4.2+4 . n$ & $\ldots$ & $\ldots$ & $\ldots$ \\
\hline 4.1. Selecting suppliers & $\cdots$ & $\cdots$ & $\ldots$ & $\ldots$ \\
\hline 4.2. Launching and receiving orders & $\cdots$ & $\cdots$ & $\cdots$ & $\cdots$ \\
\hline 4.3. Storing materials & $\cdots$ & $\cdots$ & $\cdots$ & $\cdots$ \\
\hline 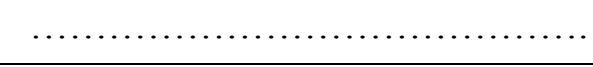 & $\ldots$ & $\cdots$ & $\cdots$ & $\ldots$ \\
\hline 5. Profit or loss & $3-4$ & $\ldots$ & $\ldots$ & $\ldots$ \\
\hline
\end{tabular}

Customer profitability can be calculated by the same approach. Then we proceed to adding the previous activities related to marketing. Traditional approaches do not identify the conditions of their own customers and sales channels. This does not happen in the case of the $\mathrm{ABC} / \mathrm{ABM}$ method. If conventional methods of management accounting and cost calculations, the profit and loss account resulted from exploitation was as follows: 
Table 3. Construction model according to the classical methods of management accounting and cost calculation

\begin{tabular}{|l|c|c|c|c|}
\hline \multicolumn{1}{|c|}{ Explanations } & $\begin{array}{c}\text { Method of } \\
\text { calculation }\end{array}$ & $\begin{array}{c}\text { Product } \\
1\end{array}$ & $\begin{array}{c}\text { Product } \\
2\end{array}$ & $\begin{array}{c}\text { Product } \\
3\end{array}$ \\
\hline 1. Turnover (Revenue from sales) & $\ldots$ & $\ldots$ & $\ldots$ & $\ldots$ \\
\hline 2. Cost of materials & $\ldots$ & $\ldots$ & $\ldots$ & $\ldots$ \\
\hline 3. Margin on direct costs & $(3=1-2)$ & $\ldots$ & $\ldots$ & $\ldots$ \\
\hline 4. Direct production costs & $(4=5+6+7)$ & $\ldots$ & $\ldots$ & $\ldots$ \\
\hline $\begin{array}{l}\text { 5. Rationally allocated indirect } \\
\text { production costs }\end{array}$ & $\ldots$ & $\ldots$ & $\ldots$ & $\ldots$ \\
\hline 6. Administrative costs & $\ldots$ & $\ldots$ & $\ldots$ & $\ldots$ \\
\hline 7. Distribution costs (commercial) & $(8=3-4)$ & $\ldots$ & $\ldots$ & $\ldots$ \\
\hline 8. Exploitation result & & $\ldots$ & $\ldots$ & $\ldots$ \\
\hline
\end{tabular}

The similarities between the way of construction of profit and loss accounts, according to the classical methods of management accounting and cost calculation and $\mathrm{ABC}$ method is as follows: (1) in terms of construction, both types of accounts address, usually, the profit and loss account list type, and (2) both models start from the separation of the two major cost categories: direct costs and indirect costs.

The differences between the way of construction of profit and loss accounts, according to the classical methods of management accounting and cost calculation (i.e. global method, the phase method, commands method etc.) and $\mathrm{ABC}$ method are identified from three points of view:

1. In terms of cost breakdown: according to the classical methods the costs are divided into two broad categories: direct costs and indirect costs. In turn, the indirect costs are divided into: Indirect costs of production, administration, sales. According to the ABC method the costs are divided into two broad categories: direct costs and indirect costs (the activities). In turn, activity-based costs are broken down by type of activity.

2. In terms of the allocation of expenditure: according to the classical methods in allocation of the indirect costs the arbitrary criteria is used. According to the $\mathrm{ABC}$ method in allocation of costs the cost drivers, based on a cause-effect relationship, are used.

3. In terms of users: according to the classical methods the final result is distorted due to the use of arbitrary criteria, which leads to the use of cost determined incorrectly. According to the $\mathrm{ABC}$ method the final result is determined fair and relevant, thanks to the use of specific criteria for the allocation of costs (cost drivers).

\subsection{ABC Dashboard}

$\mathrm{ABC}$ Dashboard is a way of framing, selection, arrangement and presentation of indicators obtained by calculating the costs under the $\mathrm{ABC}$ method, which allows the visualization of 
the overall trends in the evolution followed by the company management in their objectives. One can consider this dashboard of measures as a subset of the more comprehensive Balanced Scorecard (described below in C) that is strategic and includes non-financial key performance indicators (KPIs).

The objectives of a dashboard can aim at developing analysis that are useful for business strategies or optimization of each function of the enterprise by optimizing the operation of each component service. ABC dashboard includes a system of indicators expressed in absolute and relative sizes, used for evaluation, control and operative regulation of a business activity. Those items of information, representative in relation to certain objectives, that result from tangible measurement or observation of conditions, events or developments are called steering indicators. They are a useful data source for all hierarchical levels. Each of the branches of steering indicators is divided as follows (Ravignon et. all, 2003, p. 184):

- Steering indicators of activities and processes that measure the actions carried out within the defined strategy for achieving functional services;

- Strategic steering indicators that measure action against competitors and competitive environment;

- Steering indicators of the results which measure the degree of fulfillment of exploitation objectives.

The following principles are the basis for $\mathrm{ABC}$ dashboard:

1. The principle of consistency and appropriateness of information. According to this principle, the information provided by a dashboard must comply with the hierarchical lines established in accordance with the organization of business enterprise and its transversal organization. Dashboard elaboration at a department's level with identical positions gathers information based on the same definition and measurement of performance indicators, using a common database. The information contained in the $\mathrm{ABC}$ dashboard must be relevant, adequately reflect reality and allow taking appropriate decisions (Chiapello, Lebas, 2001, p.3). The number of selected indicators (focused on performance decision centers) must be rational, so that information obtained is relevant and concise, summarized and adapted to hierarchical levels.

2. The principle of efficiency provided information. According to this principle, the information contained in the dashboard must be analyzed and interpreted (especially the negative deviations from the target measures) and a series of corrective actions designed as well as measures to implement them.

3. Principle of standardization information. According to this principle, the information relates to the objectives, previous results and assumptions. Deviations from targets obtained at the level of departments or work centers are determined, calculated, reported and interpreted on this basis.

4. The principle of frequency of obtaining and disseminating information. The method of preparation and dissemination of the information from dashboards influence the duration of 
the decision-making process within departments or at the management level. In other words, accuracy and speed of production and dissemination of the dashboards to decision-making bodies, influence decision making and ultimately the success or failure of the business.

In the Activity-Based Costing ( $\mathrm{ABC}$ ) method, all enterprise resources are consumed by work activities. It is important that the indicators studied cover the entire business area. Identification of relevant indicators for measuring enterprise performances are suggested and determined mainly by the level of the activities. For most companies, it was found out that the indicators focus primarily on direct labor, which is particularly important for the overall used resources. But labor expenses, including indirect and shared expenses, are also reflected in the production, marketing or administration sector. In general, the activities of an enterprise are evaluated by the ABC (Activity-Based Costing) method through indicators such as: level of activity, level of cost, unit cost of an output, efficiency, effectiveness, non-quality etc. They will be established and followed monthly by Specifications of indicators. For example, indicators of activities levels are targeted to their objective value. Indicators of efficiency and effectiveness are compared with objectives. Finally, quality indicators help to compare the reliability of activities compared to total quality objective. According to specialists, we can identify several categories of indicators such as (Ravignon et. all, 2003):

1. Indicators related to the volume or activity level. These indicators express the volume of work produced during a defined period or an estimated point of the same type. They measure, for the sake of improvement, the level of activity (usually the number of "outputs" provided). There may be taken into account the number of contacts with customers, suppliers, internal and external collaborations, deliveries (monthly or quarterly) etc. performed by an enterprise. The purpose of these indicators is to reveal the volume drawn from contacts with partners in a defined period of time (monthly or quarterly). There also may be taken into account longer periods of time (e.g. 1 year), but the results are intended to make decisions on short time as fast and efficient as possible. The general form these indicators can take is:

\section{$\frac{\text { Cost drivers }}{\mathrm{N}}$}

Where: $\mathrm{N}=$ number of time periods.

2. Indicators related to objectives of efficiency and effectiveness. The definitions of the two concepts are based on the difference between them. Efficacy is the ability to obtain the desired objectives, while efficiency is minimization of the means used by employees for a given result. In other words, efficiency helps us know the results of objectives, while that efficiency helps us to know whether the objectives are met in relation to the initially designed budget. Indicators related to efficiency objectives reflect the turnover changes in to the changes of costs drivers used by an enterprise. The general form these indicators may take is:

$\mathrm{I}_{\text {Efficacity }}=\frac{\overline{\mathrm{T}} \mathrm{N}+1-\overline{\mathrm{T}} \mathrm{N}}{\overline{\mathrm{T}} \mathrm{N}} \times 100$ 
$\overline{\mathrm{T}} \mathrm{N}=\frac{\mathrm{T}_{\mathrm{N}}}{\text { Cost driver }}$

Where: $\overline{\mathrm{T}}=$ The average turnover per job; $\mathrm{N}=$ number of time periods.

Subunit effectiveness indicators signify the company's ability to successfully meet the objectives (positive deviations) while indicators of supraunit effectiveness indictors indicate failure to achieve business goals (negative deviations, in case of failure of the objectives). Indicators related to objectives of efficiency reflect changes in hourly variations in cost drivers used by an enterprise. The general form these indicators may take is:

$\mathrm{I}_{\text {Efficiency }}=\frac{\overline{\mathrm{Vh}} \mathrm{N}+1-\overline{\mathrm{Vh}} \mathrm{N}}{\overline{\mathrm{Vh}} \mathrm{N}} \times 100$

$\overline{\mathrm{Vh}} \mathrm{N}=\frac{\mathrm{Vh}_{\mathrm{N}}}{\text { Number of orders }}$

Where: $\overline{\mathrm{Vh}}=$ Average number of hours per job; $\mathrm{N}=$ number of time periods.

Subunit efficiency indicators express the enterprise's inability to achieve business objectives in quantitative terms (negative deviations), while the supraunit efficiency indicators means the enterprise's ability to achieve its objectives (positive deviations).

3. Indicators related to objectives of quality (or non-quality). These indicators measure the level of reliability (or non-reliability) of an activity in relation to the total quality objective. It serves to calculate the non-quality costs. The form these indicators may take is:

Cost driver(activity $1 . . . \mathrm{n})$

Cost driver(objective)

Where: $1 \ldots \mathrm{n}=$ number of activities in the list (catalog business, target = total quality $(100 \%)$.

4. Indicators related to cost objectives. These indicators will measure the development cost and resources consumed by an activity. They allow the investigation of a possible outsourcing of the sub-activity. The general form these indicators may take is:

\section{$\frac{\text { Cost }}{\text { Cost driver }}$}

Where: $\operatorname{cost}=$ activity cost; $\quad$ Cost driver $=$ specifics of the activity (product).

5. Indicators related to delivery terms objectives. These indicators measure the delays in performance and on that basis; participate in the measurement of normal value per customers. 
The general form these indicators may take can be expressed as follows:

$360-\left(\frac{\text { Invoiced value }}{\text { Turnover }} \times 360\right)$

For example, late deliveries to customers are differentiating elements. At a price equal between two suppliers, a customer will choose the company that delivers as soon as possible. It undoubtedly helps us to: distinguish delays incurred into key success factors of that market, identify strengths and weaknesses relative to competitors, improve speed of delivery in other activities, in a logical process, measure progress with indicators of delay, and highlight the element of differentiation to customers (normal quality). Dashboard presents in its structure: tables of values, graphs or a combination of the two. This form is shown below:

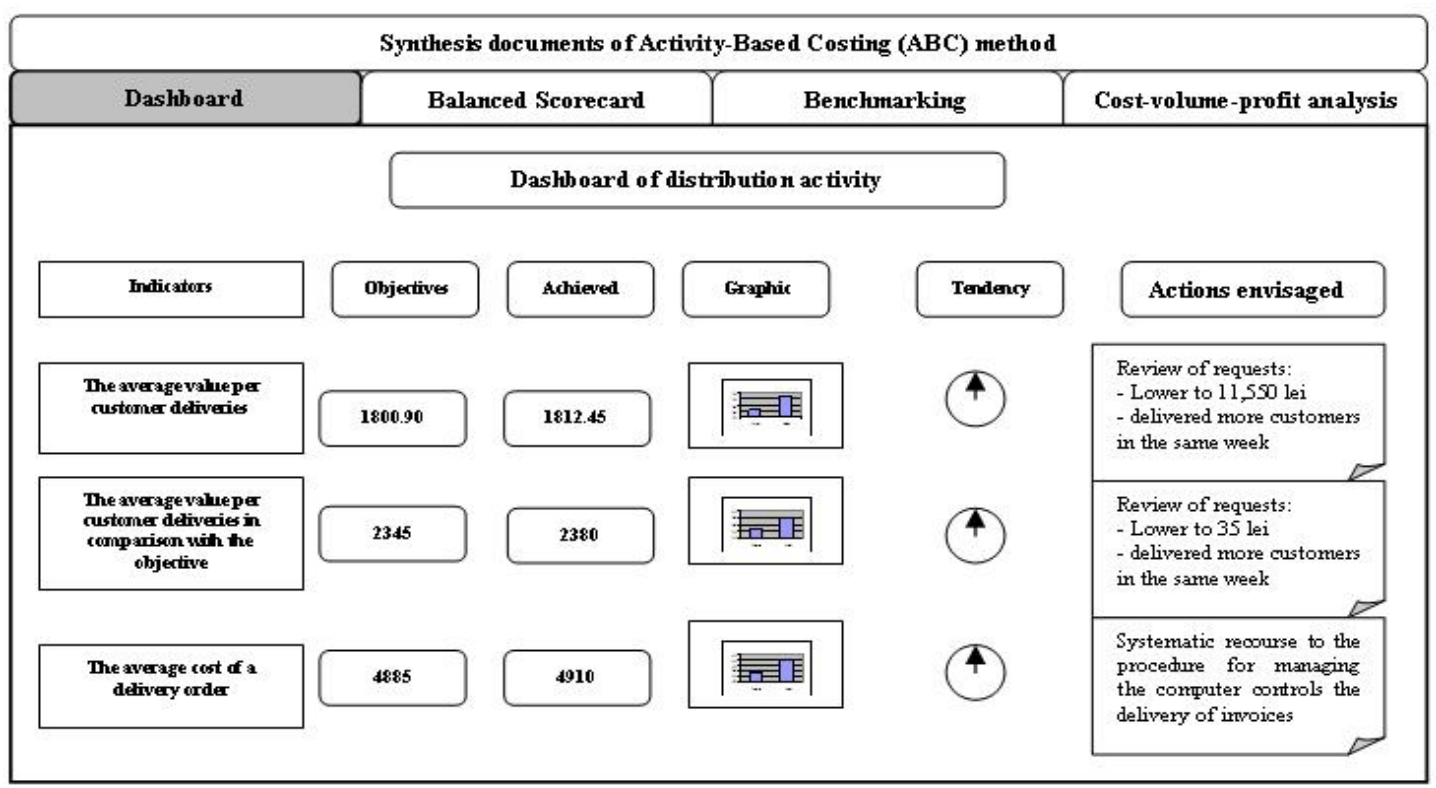

Figure 3. Analysis of dashboard indicators

Permanent knowledge of the status and evolution of the indicators set out in the dashboards oriented objectives allow management to contribute to the improving of the enterprise performance. Information included in dashboards should be made available to other departments or operational services, so that the final decision taken at management level be more rigorously grounded and take into account the opinions and conclusions of all those involved the smooth running of the company.

\subsection{Balanced Scorecard}

Balanced Scorecard consists of a set of indicators related to the enterprise strategy that gives the opportunity of steering performances on its components, combining the non-traditional financial instruments with the financial instruments, thus providing managers with relevant information on the activities conducted by them (Kaplan and Norton, 1992, 1993, 1996ab, $2000 \mathrm{ab}, 2001 \mathrm{ab}$ ). This balanced scorecard can be easily adapted to the requirements of the 
$\mathrm{ABC}$ method, according to the information needs of managers from the point of view of the objectives set. According to its authors, Robert Kaplan and David Norton, the balanced scorecard is a strategic approach and a performance management system that enables organizations to translate their visions and strategies into action, in terms of four perspectives: financial, customers, learning \& growth and internal business.

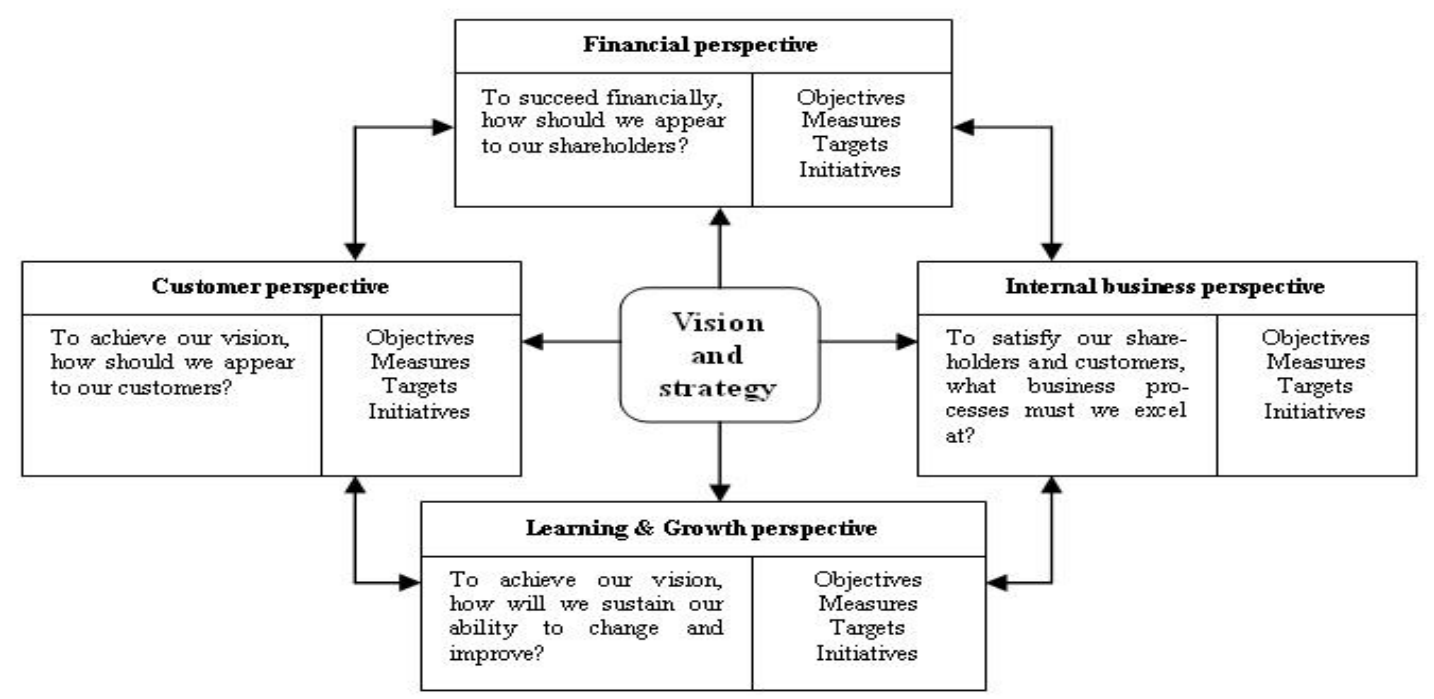

Figure 4. Balanced Scorecard

Adaptation after Kaplan and Norton, 1996, The Balanced Scorecard, Harvard Business Press: 9, Original from HBR Jan/Feb, 1996, p. 76.

1. Financial perspective. Basic information obtained in a timely manner will always be a priority, and managers will do whatever is necessary to provide it. In fact, many times, handling and processing of financial data is more than enough. Once a corporate database established, much data processing can be centralized and automated. But the idea is that the current emphasis placed on financial statements creates an "unbalanced" situation, with regard to other perspectives. There is a need to include this category of additional financial data, such as risk assessment, gross margin, net income or cash flow.

2. Customer perspective. Recent management philosophy has shown an increasing achievement of two indicators showing success in any business: customer orientation and customer satisfaction. Poor performance due to the degree of customer dissatisfaction is a main indicator of future decline, even if the current financial picture may look better. In developing measurements of the satisfaction degree, customers should be analyzed in terms of customer types that are offered a product or a service (Niven, 2002, p.9).

3. Internal business perspective. Measurements based on this perspective allow the managers to know how well they run their business, and if their products and services comply with customer requirements. These measurements must be carefully drafted by those who know these processes in detail. In terms of strategic management, two types of internal processes 
can be identified: mission oriented processes and support processes, much easier to measure and compare the generic measurements.

4. Learning\&growth perspective. This includes both employee training and cultural attitudes related to individual self-improvement and corporate improvement. In an information structure based on workers, people are the main resource. In the current environment of rapid technological changes, it becomes necessary for knowledgeable workers to be in a continuous way of learning. A Kaplan and Norton point out that "learning" is more than "training" as it includes also mentors and tutors within the entity, and it facilitates communication among workers, allowing them to easily obtain help in a problem when needed (Kaplan and Norton, 1996). It may also include, technological tools, such as intranet. A possible form that a balanced scorecard may take is shown in the figure below (Figure 5).

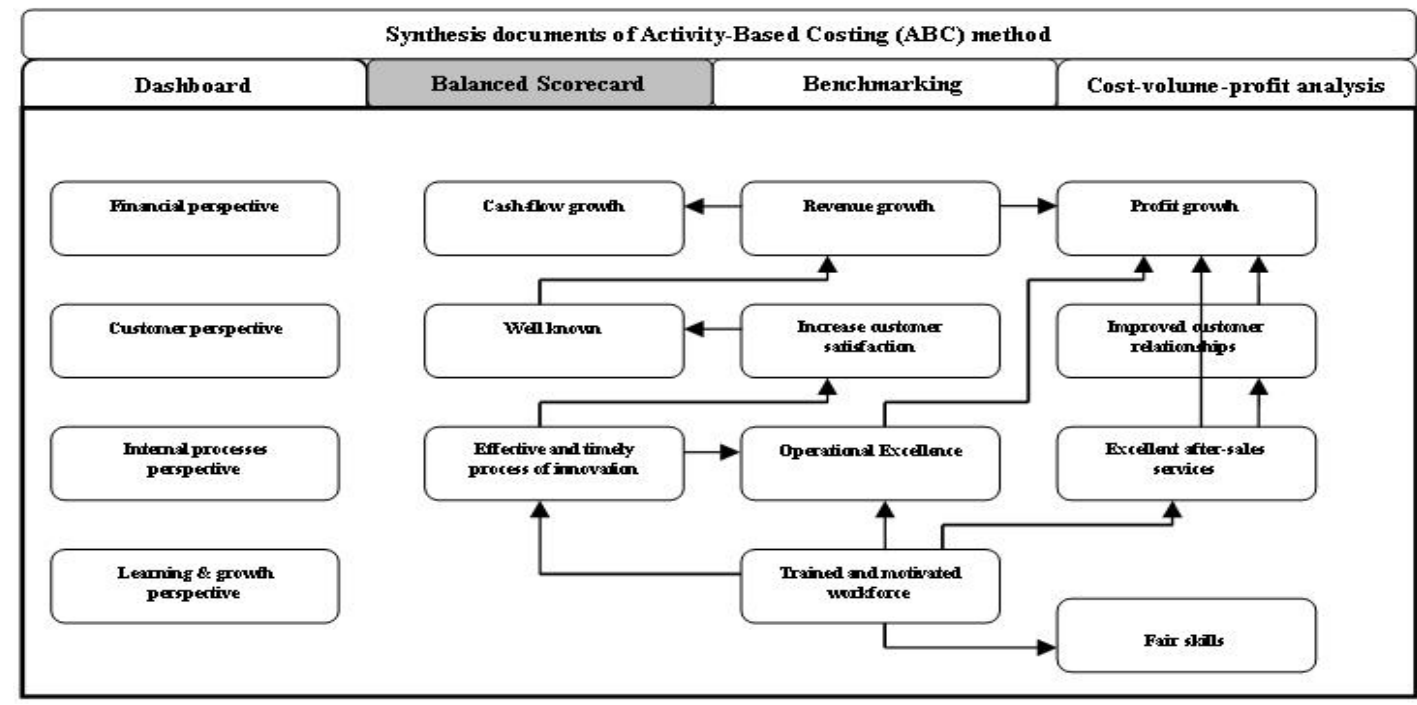

Figure 5. Balanced Scorecard incorporated in a synthesis document of the ABC method

\subsection{Benchmarking}

Benchmarking is the process by which an entity compares its performance and practices with those of one or more entities (either internal like bank branches, or external with other companies). Its objective is to identify best practices that will improve its performance. In other words, for an entity, benchmarking is a tool for self-improvement that enables comparison with other competitors and thus identification of strengths and weaknesses and allows learning how to improve them (Briciu and all, 2010, p. 409).

Benchmarking is a performance or a functional objective that allows achieving of an excellent level of quality, performance, cost and speed. It is necessary that the processes, products or services be measured comparatively to other processes, products or services recognized as the best in the world. Benchmarking is a structured approach that involves collecting data (through questionnaires), analysis and reporting. The questionnaire may require qualitative or quantitative data or a combination of both. Data collection can range from simple on-site visits (time consuming) to type on-line polls (much faster). Data analysis 
result is a benchmark against which one can compare the performance of the entity and improvements targeted. Thus, benchmarking helps explain the processes underlying the performances. If the lessons learned from the benchmarking exercise are applied appropriately, they facilitate improved performance in critical functions of an entity or key business areas. Application of benchmarking involves four main steps (Boxwell, 2005):

1. Detailed understanding of internal processes;

2. Analyzing of the internal processes of other entities;

3. Comparing its performance with those of other analyzed entities;

4. Implementation of measures to eliminate performance gaps.

Benchmarking should not be regarded as an exercise to be performed once. To be effective, it must become an integral part of a continuous improvement process for updating with best practices in the field. Three major categories of costs are included with benchmarking:

1. Travel costs include costs related to accommodation, travel, meals, gifts symbolic and lost labor time.

2. Costs of extra-time. The benchmarking team will work extra time in researching problems, finding exceptional companies to study visit and apply.

3. Database-related costs associated to benchmarking. Organizations use benchmarking in their daily procedures find it useful to create and maintain a database of best practices and their associated companies.

Benchmarking costs can be reduced considerably by using multiple Internet resources that have emerged over recent years. These benchmarks follow and capture best practices from countries, entities, business sectors to make the benchmarking process much faster and cheaper. The form benchmarking may take is:

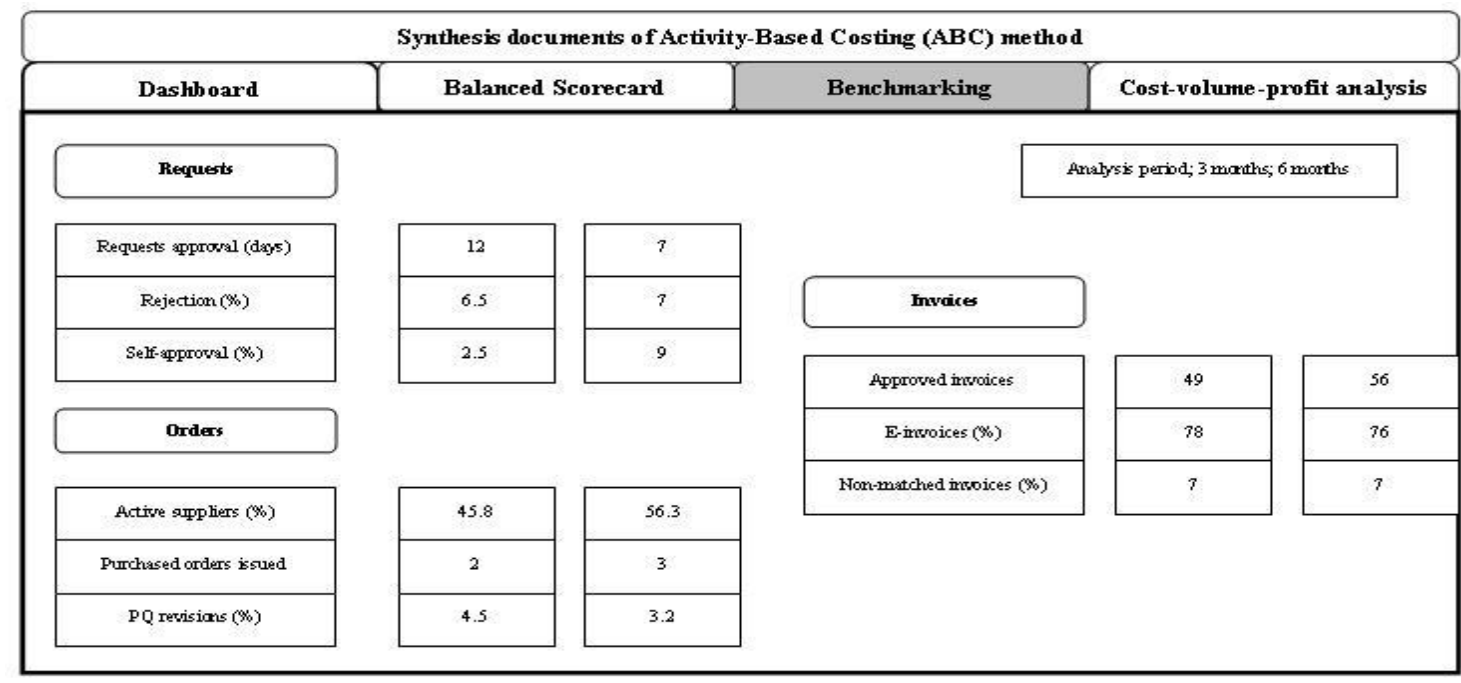

Figure 6. Benchmarking incorporated in a synthesis document of the $\mathrm{ABC}$ method 


\subsection{Cost-volume-profit-analysis}

Cost-volume-profit analysis focuses on research and analysis of the break-even point, the relationship between prices and volume of activity, unit variable cost, total fixed costs and balance of mixed production, planning and decision making the management of an entity. (Araujo, 1999). Before analysis, the costs of an entity are classified into: fixed expenditures and variable expenditures.

Breakeven point is the point where profit is zero or is equal to revenues and expenses. Knowing the breakeven point or the balance point helps us to know the start point for an entity to obtain profit and to cover its fixed expenditures and variable expenditures. The breakeven point is calculated according to the equation (Briciu and all, 2010, p. 360):

Breakeven point $=\frac{\text { Fixed expenses }}{\text { Grosscontribution per unit }}$

Where:

Gross contribution per unit $=\frac{\text { Contribution to total gross }}{\sum \text { Salequantity }}$

Gross contribution is the difference between turnover and variable expenses. The result is determined as the difference between gross contributions and the total fixed costs.

Determination of the breakeven point from the total cost involves the OX axis representation of the turnover or of the activity level, and the OY axis of the total cost, margin and fixed costs. The intersection of two lines previously determined, for known values, will establish the breakeven point, as shown in the figure below:
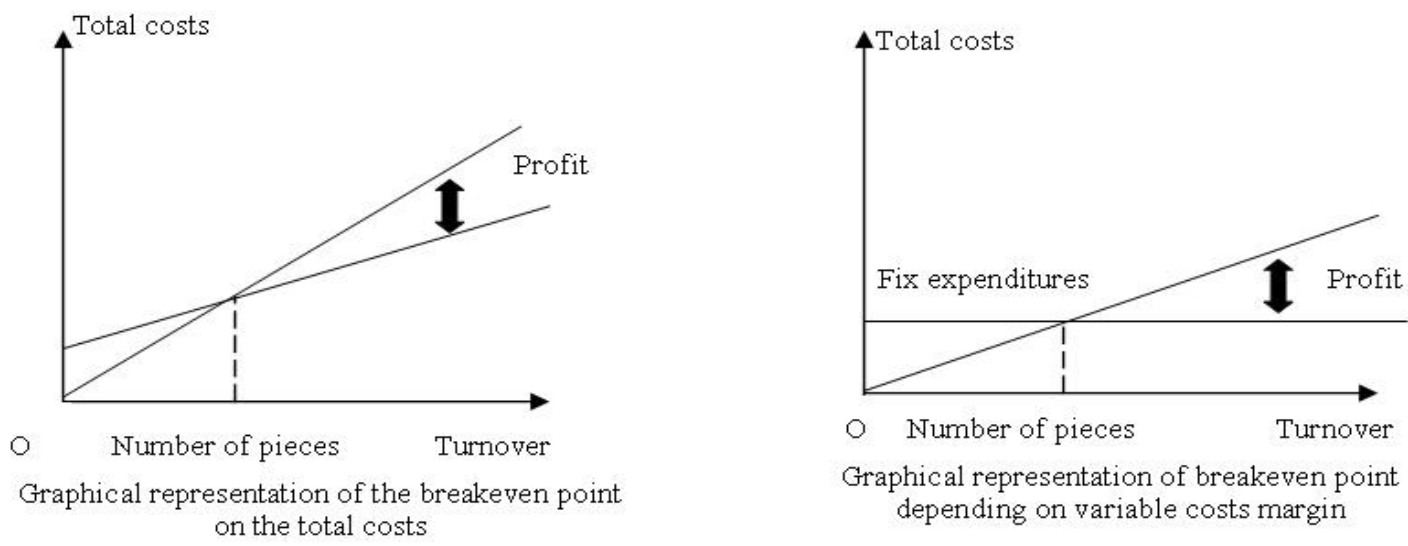

Figure 7. Graphical representation of the breakeven point

Taking into account the principle of the $\mathrm{ABC}$ method, under which "no cost is fixed, all costs are variable, if their origin is carefully investigated" (Bouquin, 1997, p. 78), then we can identify the variable costs (VC) as consisting of both direct costs and the activities costs (indirect), the margin on variable costs is deducted as follows:

MVC $=$ Turnover - Total variable costs (Direct costs + Activities costs) 
Comparing the breakeven point obtained by the traditional method (classical) and the $\mathrm{ABC}$ method, we find that in the first case, the breakeven point can be measured both in volume and value (lei), while if the $\mathrm{ABC}$ method, break-even point is determined from a quantitative perspective, the latter explanation lies in the principle of the $\mathrm{ABC}$ method.

Contributory factor or margin coverage. This indicator underlines the extent to which a product or command(s) are profitable for an enterprise, in terms of coverage of costs and profits obtained. The contributory margin per job or the coverage factor is determined according to the relation (Briciu and all, 2010, p. 360):

Contributory margin $=\frac{\text { Gross contribution }}{\text { Turnover }} \times 100$

With the ABC method, we can detect those products that may not cover costs and are not profitable to the entity. Both through the classical method and $\mathrm{ABC}$ method, identification of unprofitable products is about the same, but the $\mathrm{ABC}$ method shows the real coverage of production costs and the profit per product. The concentration of a very small number of indirect costs in the structure of the total cost, through the classical method, has led to a distortion of the accounting information. Another cause is due to the use of unjustifiable criteria in terms of cause and effect relationship between costs and the amount allocated for distribution bases, frequent in traditional methods.

Cost behavior may change because of the shift from a traditional cost accounting system to the $\mathrm{ABC}$ system. In traditional methods, cost-volume-profit analysis requires a single cost driver, namely, the volume of sales. With costs having more cost drivers used by the $\mathrm{ABC}$ method, some traditional fixed costs are now considered variables costs (from the point of view of appropriate cost drivers). The $\mathrm{ABC}$ method managed to reflect the real contributory level product margins, which leads to taking appropriate decisions by company management.

\section{Advantages and disadvantages of the components of the synthesis documents}

The five tools analyzed have some advantages that recommend them as one of the most effective tools for monitoring and measuring performance specific of Activity/Based Costing (ABC) method and not only, they are the real basis underlying the decisions taken by managers of an entity. Among the benefits of the results account (Diaconu, 2003):

- it provides a clear view of the consumption of resources by the activities and consumption of activities by cost objects;

- it is not a fixed format, but a database that can be modeled according to the information needs, products can be detailed on projects, customers, strategic segments;

- it explains how training costs and the cost of value provided to customers shape themselves. Depending on its requirements, we can see, based on the scale of activities, the solutions to improve quality or to reduce cost.

Among the benefits of the dashboard and balanced scorecard (Briciu and all, 2010, p.414):

- By taking into account the four different perspectives of the balanced scorecard and viewing 
them as a whole, the management company ensures a balanced perspective of its performances;

- short term, medium and long term views are managed continuously and cohesively both on the dashboard and the balanced scorecard;

- Strategies formulated by senior management and the actions taken at the department level are focused and clearly linked between them;

- Enterprise performance reporting focuses on issues necessary for the enterprise to remain competitive in the long term and to reflect the achievement of value for stakeholders.

Among the advantages of benchmarking we can mention: identification of areas that need performance improvement, identification of risks, contribution to continuous improvement, measures to meet the audit requirements to ensure compliance and to meet the requirements of the regulatory authority, monitoring and reviewing of the progress, improved quality.

Cost-volume-profit analysis has several advantages including:

- cost-volume-profit analysis is used to find the most profitable combination of variable costs, fixed costs, selling prices and sales volume. Profits can sometimes be improved by reducing the contribution margin where fixed costs can be reduced by a higher amount;

- The accuracy of calculating costs of the $\mathrm{ABC}$ method provides an entity with a better understanding of cost behavior and cost-volume-profit relationship.

\section{Conclusions and future research recommendations}

The set of synthesis accounting documents presented represents a facility and accelerate the decision of a manager. With these synthesis accounting documents, a manager can operate at several levels and take very important management decisions in the short term as in the long therm, especially since the effectiveness of decisions is based on reliable and properly analyzed data. Arguments proposed by us are based on the benefits offered by each of the instruments used to collect, control and analyze cost, whose accurate information obtained contribute to the comprehensive decision-taking of the managers, regardless of their location within a hierarchical entity. Also, the surveys based on questionnaires demonstrate the importance both experts and managers of information concentrated in a single document give to it, and, we believe, in time it will prove itself truly useful. Involvement of the management in the drafting and the use of these synthesis accounting documents is of major importance while awareness of both management and the others involved will help ensure the future success of the entity and obtain superior performance.

We are hoping that our view on the importance and efficiency of synthesis documents specifically to $\mathrm{ABC}$ method has been correctly received both in business and in academia, we express our desire to improve and expand the area of analysis of these instruments expanding collaboration in training through continuous media coverage of the results of scientific research in this area particularly important as managerial accounting. 


\section{Macrothink}

International Journal of Accounting and Financial Reporting

ISSN 2162-3082

\section{Acknowledgement}

This research study has been completed under the supervision of Mr. Gary Cokins, from SAS Institute Inc., Cary, North Carolina, USA. We are very thankful to him for his valuable suggestions and encouragement. We are also very thankful to $\mathrm{PhD}$ Professor Sorin Briciu from 1 Decembrie 1918 University of Alba Iulia, Romania, for providing us with a platform of learning and to conduct this research study. 


\section{References}

Briciu S., CÄfpuÅŸneanu S., Rof L.M., Topor D. (2010). Accounting and management control. Entity performance assessment tools, Aeternitas Publishing House, Alba-Iulia. CÄfpuÅŸneanu S. (2008). Elements of cost management, Economic Publishing House, Bucharest.

Chiapello E., Lebas, M. (2001). The Tableau du Bord, a French Approach to Management Information, European Accounting Association Conference, May 2-4.

Cokins G., CÄfpuÅŸneanu S. (2010). Cost drivers. Evolution and benefits, Theoretical and Applied Economics, no. 8, pp. 7-16.

Cokins G. (1996). Activity-Based Cost Managementâ "Making it work â " A managerâ ${ }^{\mathrm{TM}_{\mathrm{S}}}$ guide to implementing and sustaining an effective $\mathrm{ABC}$ system, The McGraw-Hill Companies, Inc.

Collis J., Hussey R. (2007). Business Accounting, an introduction to financial and management accounting, Palgrave MacMillan, New York.

Epstein, M.J., Manzoni, J.F. (1997). The Balanced Scorecard and Tableau de Bord: Translating Strategy into Action, Management Accounting, Vol. LXXIX, No. 2, pp. 28-36.

FeleagÄ $f$ N. (2000). Compared accounting systems. Vol. I and II, Economic Publishing House, Bucharest.

Gray J., Pesqueux Y. (1993). Evolution actuelles des syst ̃̃"mes de tableau du bord. Comparaison des pratiques de quelques multinationales amÃ Cricaines et fran $\tilde{A} \S a i s e s, ~ R e v u e$ FranÃ §aise de ComptabilitÃ (), No 242, pp. 61-70.

de Guerny J., Guiriec J. C., Lavergne, J. (1990). Principes et mise en place du Tableau de Bord de Gestion, 6th Edition, Paris 1990.

Helfert E. A. (2001). The Nature of Financial Statements: The Income Statement. Financial Analysis - Tools and Techniques-A Guide for Managers, McGraw-Hill.

Kaplan R.S., Norton D.P. (1992). The Balanced Scorecardâ "Measures That Drive Performance, Harvard Business Review, Jan-Feb 1992, pp. 71-79.

PMid:10119714

Kaplan R.S., Norton, D.P. (1993). Putting the Balanced Scorecard to Work, Harvard Business Review, Jan-Feb 1992, pp. 134-147.

Lebas, M.(1994). Managerial Accounting in France: Overview of Past Tradition and Current 


\section{Macrothink}

International Journal of Accounting and Financial Reporting

ISSN 2162-3082 2011, Vol. 1, No. 1

Practice, European Accounting Review, Vol. 3, No. 3.

http://dx.doi.org/10.1080/09638189400000032

Ministry of Finance, Accounting Law no. 82/1991, republished in 2008, updated in 2010.

Niven P. R. (2002). Balanced Scorecard. Step-by-Step. Wiley \& Sons, p. 9.

Ravignon L., Bescos P.L., Joalland M., Bourgeois S.Le, MalÃ@jac A. (2003). MÃ@thode ABC/ABM, Ed. Dâ TMOrganisation, Paris. 